\title{
Medical Image of the Week: Pulmonary Artery Sling
}

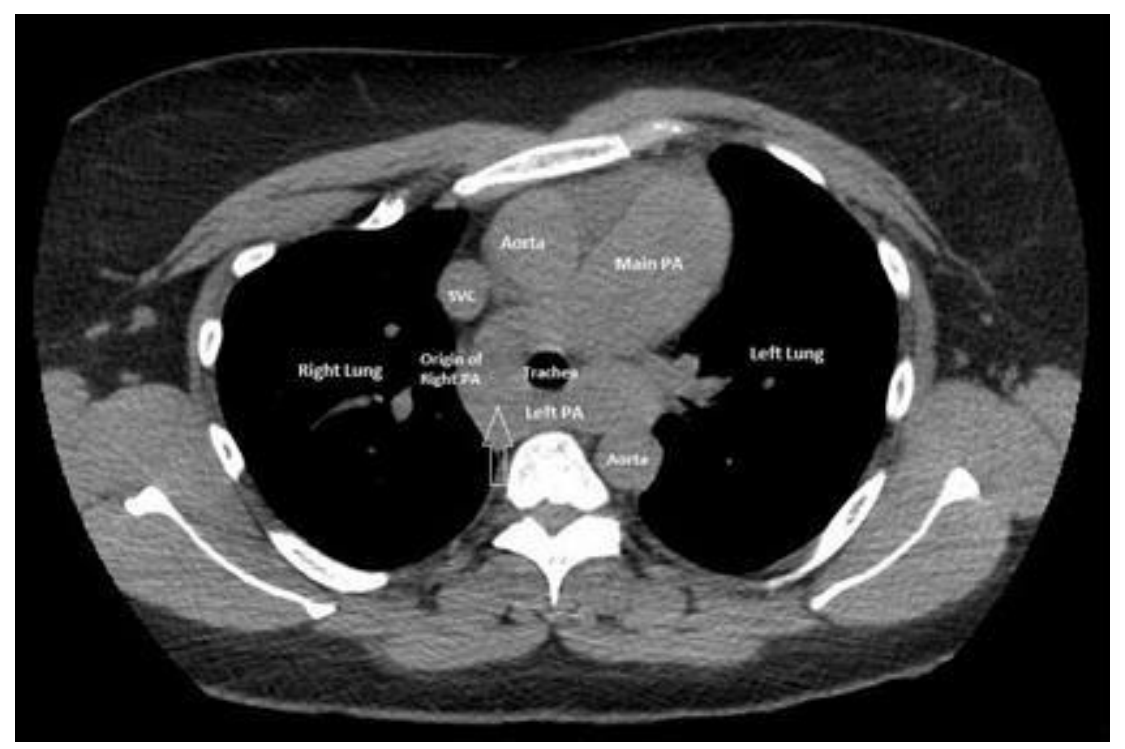

Figure 1. Computerized tomography (CT) of the chest showing the aberrant origin of the left pulmonary artery from the right pulmonary artery creating a pulmonary artery sling with mild tracheal narrowing (arrow).

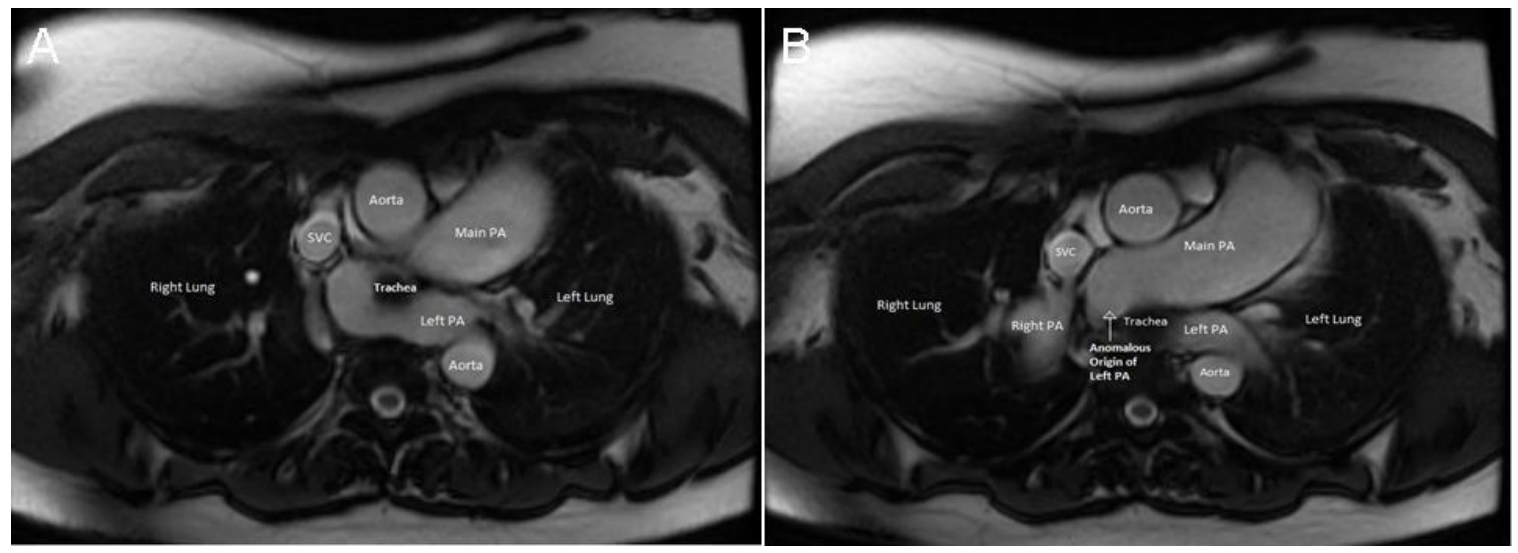

Figure 2. Cardiac magnetic resonance imaging (MRI) confirming the presence of a pulmonary artery sling with aberrant origin of the left pulmonary artery from the right pulmonary artery.

A 42-year-old year woman with asthma was admitted to the hospital with an asthma exacerbation. The patient complained of dyspnea on exertion, two-pillow orthopnea and bipedal edema. An echocardiogram showed a severely dilated right ventricle (RV) with elevated right ventricular systolic pressure of $71 \mathrm{mmHg}$. The systolic left ventricular (LV) function was also reduced with an ejection 
fraction of $45 \%$. Computerized tomography (CT) of the chest showed an aberrant origin of the left pulmonary artery (PA) creating a pulmonary artery sling with mild tracheal narrowing (Figure 1, arrow). Cardiac magnetic resonance imaging (MRI) confirmed the presence of a pulmonary artery sling with the aberrant origin of the left PA from the right PA (Figure 2). Cardiac catheterization showed a mean PA pressure of $46 \mathrm{mmHg}$ with LV end diastolic pressure of $12 \mathrm{~mm} \mathrm{Hg}$. The patient was diagnosed with WHO Group I pulmonary hypertension and started on treatment with sildenafil with a stable outpatient course.

Pulmonary artery sling is an uncommon form of vascular ring. The anomaly is a result of formation of the left PA from the right sixth vascular arch (rather than the left), leading to the left PA arising from the posterior aspect of the right PA (1). Pulmonary artery slings may produce symptoms of airway compression and esophageal compression and usually presents in childhood (2). In asymptomatic cases, a PA sling may mimic a mediastinal mass on chest radiographs and CT and MRI may be used to establish the diagnosis (3).

Abhinav Agrawal MD¹, Stuart L Cohen $\mathrm{MD}^{2}$, Rakesh Shah MD², Arunabh Talwar MD FCCP ${ }^{1}$

1Division of Pulmonary, Critical Care \& Sleep Medicine, Department of Medicine 2Division of Thoracic Radiology, Department of Radiology Hofstra-Northwell School of Medicine New Hyde Park, NY USA

\section{References}

1. Casta-er E, Gallardo X, Rimola J, Pallardó Y, Mata JM, Perendreu J, Martin C, Gil D. Congenital and acquired pulmonary artery anomalies in the adult: radiologic overview. Radiographics. 2006 Mar-Apr;26(2):349-71. [CrossRef] [PubMed]

2. Odell DD, Gangadharan SP, Majid A. Pulmonary artery sling: a rare cause of tracheomalacia in the adult. J Bronchology Interv Pulmonol. 2011 Jul;18(3):278-80. [CrossRef] [PubMed]

3. Ganesh V, Hoey ET, Gopalan D. Pulmonary artery sling: an unexpected finding on cardiac multidetector CT. Postgrad Med J. 2009 Mar;85(1001):128. [CrossRef] [PubMed] 